\title{
EFFECTS OF CLIMATIC PERTURBATIONS ON THE SURFACE-ABLATION REGIME OF THE GREENLAND ICE SHEET, WEST GREENLAND
}

\author{
By W. АМвACH
}

(Institut für Medizinische Physik, A-6020 Innsbruck, Austria)

\begin{abstract}
The shift of the equilibrium-line altitude by climatic perturbations of air temperature $\delta T_{\mathrm{a}}$, absolute humidity $\delta \rho_{\mathrm{y}}$, cloudiness $\delta w$, and annual accumulation $\delta c$ in West Greenland (EGIG profile) is analyzed by heat-balance modelling. The perturbations $\delta T_{\mathrm{a}}=+1 \mathrm{~K}, \delta \rho_{\mathrm{v}}=+0.25 \mathrm{~g} \mathrm{~m}^{-3}$, $\delta c=+50 \mathrm{~kg} \mathrm{~m}^{-2}$ result in a shift of the equilibrium-line altitude of $87.5,9.8$, and $-24.3 \mathrm{~m}$, respectively, while perturbations in cloudiness are negligible. The most important influence originates from changing air temperature, as air temperature affects daily heat-flux density of melt and duration of the ablation period. In regimes with negative values of the gradient of annual accumulation, the shift of the equilibrium line is enhanced.
\end{abstract}

\section{INTRODUCTION}

The shift of the equilibrium-line altitude and the increased melting in the ablation area of the Greenland ice sheet have been discussed repeatedly in relation to the rising concentrations of $\mathrm{CO}_{2}$ and other greenhouse gases in the atmosphere (National Academy of Sciences, 1985; Oerlemans, 1989). Heat-balance characteristics measured in the ablation area in West Greenland (Camp IV-EGIG, $1013 \mathrm{~m}$ a.s.l., lat. $69^{\circ} 40^{\prime} \mathrm{N}$., long. $49^{\circ} 38^{\prime} \mathrm{W}$; A mbach, 1963 , 1985a) allow calculation of the influence of climatic perturbations on the equilibrium-line altitude and the ablation regime. The analysis is based on earlier work by Kuhn (1980). Whereas in previous papers, changes of the ablation period (Ambach, 1985b) and of the latent heat-flux density (Ambach, 1985b, 1988; Ambach and Kuhn, 1989) were not taken into account, these terms are involved in the present paper.

\section{LIST OF SYMBOLS}

$c$ Annual cumulative accumulation

$f$ Non-dimensional number

$H$ Heat-flux density

$h$ Thickness of snow (ice) layer

$\Delta h$ Difference in altitude related to present equilibriumline altitude

$k \quad$ Non-dimensional number

$L \quad$ Specific heat of melting

$Q \quad$ Heat of melting per unit area of the ablation period

$Q^{*}$ Heat of melting per unit area of the ablation period integrated over the altitude

$T_{\mathrm{a}} \quad$ Air temperature

$W$ Water equivalent

$w$ Cloudiness

$z \quad$ Altitude

$\alpha, \alpha^{\prime}$ Factor of proportionality

$\beta \quad$ Factor of proportionality

$\gamma \quad$ Factor of proportionality

$\mu \quad$ Factor of proportionality

$\rho$ Density

$\rho_{\mathrm{y}}$ Absolute humidity

$\tau$ Number of ablation days

$\varphi \quad$ Factor of proportionality

\section{ABLATION-DAYS METHOD}

At the equilibrium line, annual cumulative accumulation and annual cumulative ablation are equal at the end of the balance year. In that case, the heat-balance equation reads:

$$
\tau_{0} H_{0}=k L c_{0}
$$

where $\tau_{0}$ is the number of ablation days ( $d$, number of days with averaged air temperature $\left.\geqslant 0^{\circ} \mathrm{C}\right), H_{0}$ is the averaged heat-flux density of melting $\left(\mathrm{MJ} / \mathrm{m}^{2} \mathrm{~d}\right), k$ is the factor of proportionality taking into account the formation of superimposed ice explained below, $L$ is the specific heat of ice melting $(\mathrm{MJ} / \mathrm{kg})$, and $c_{0}$ is the annual cumulative accumulation $\left(\mathrm{kg} / \mathrm{m}^{2}\right)$.

The left-hand term $\tau_{0} H_{0}$ means the total heat of melting per unit area over the entire ablation period originating from the interaction between the atmosphere and the surface. The right-hand term $k L c_{0}$ means the heat required for melting of the annual cumulative accumulation including superimposed ice. The subscript zero refers to the present-day condition at the equilibrium line.

The method is called the ablation-days method, as the calculation of the heat of melting $\tau_{0} H_{0}$ is based on the number of ablation days $\tau_{0}$. The definition of ablation days as days with $T_{\mathrm{a}} \geqslant 0^{8} \mathrm{C}$ is arbitrary (Kuhn, 1987). Other suitable definitions of ablation days are $T_{\max } \geqslant 0^{\circ} \mathrm{C}$ or $T_{\min } \geqslant 0^{\circ} \mathrm{C}$. If the definition of the ablation days is changed, the value $H_{0}$ is changed simultaneously so that Equation (1) remains satisfied. The ablation-days method is therefore independent of the definition of ablation days.

A special feature of Equation (1) is the consideration of superimposed ice formation. Superimposed ice is formed when melt water refreezes on a water-impermeable surface. The heat of freezing is released and causes an increase in temperature of snow and ice layers beneath. In general, the summer ablation surface of the previous year serves as such a water-impermeable surface. Assuming conservation of mass during the transformation of melt water into superimposed ice without any loss by run-off, and assuming densities for snow and superimposed ice, the factor $k$ amounts to $5 / 3$. As a consequence, if there is complete superimposed ice formation at the equilibrium line, two-thirds more heat of melting is required compared with the simple case of no superimposed ice formation. The derivation of the value $k=5 / 3$ is given in section 4 .

\section{SUPERIMPOSED ICE FORMATION}

For the calculation of the influence of superimposed ice formation on the heat balance, the following are introduced: water equivalents of initial snow-pack before snow melt $\left(W_{0}\right)$, melted snow layer with superimposed ice formation $\left(W_{1}\right)$, and superimposed ice layer $\left(W_{2}\right)$. With the densities of $\rho_{1}=300 \mathrm{~kg} \mathrm{~m}^{-3}$ for snow and $\rho_{2}=900 \mathrm{~kg} \mathrm{~m}^{-3}$ for superimposed ice, the water equivalents are 


$$
\begin{aligned}
& W_{0}=h_{0} \cdot 300 \quad\left(\mathrm{~kg} \mathrm{~m}^{-2}\right) \\
& W_{1}=\left(h_{0}-h_{2}\right) \cdot 300 \quad\left(\mathrm{~kg} \mathrm{~m}^{-2}\right) \\
& W_{2}=h_{2} \cdot 900 \quad\left(\mathrm{~kg} \mathrm{~m}^{-2}\right)
\end{aligned}
$$

where $h_{0}$ is the initial snow depth and $h_{2}$ is the thickness of the superimposed ice layer.

In the case of superimposed ice formation at the equilibrium line, the melt is $W_{1}+W_{2}$, whereas without superimposed ice formation the melt is $W_{0}$. Using Equations $(2 \mathrm{a}-c)$, the ratio $k$ reads

$$
\begin{aligned}
& k=\left(W_{1}+W_{2}\right) / W_{0} \\
& k=1+(2 / 3)\left(W_{2} / W_{0}\right)
\end{aligned}
$$

with the following results

Complete superimposed ice formation $\left(W_{2}=W_{0}\right)$ :

$k=5 / 3$;

No superimposed ice formation $\left(W_{2}=0\right): k=1$;

Partial superimposed ice formation $\left(0<W_{2}<W_{0}\right)$ : $k=1+2 h_{2} / h_{0}$.

In Equations (3) the ratio $k$ also equals the ratio of heat of melting corresponding to the water equivalents $W_{1}+W_{2}$ and $W_{0}$. As a consequence, the heat of melting required in the case of complete superimposed ice formation is greater by a factor of $5 / 3$ compared with the case of no superimposed ice formation.

\section{CHANGE OF HEAT BALANCE BY CLIMATIC PERTURBATIONS}

\subsection{Heat of melting}

The heat balance reads

$$
H=H_{\mathrm{R}}+H_{\mathrm{S}}+H_{\mathrm{L}}+H_{\mathrm{C}}+H_{\mathrm{P}}
$$

The terms are daily heat-flux densities averaged over the ablation period $\left(\mathrm{MJ} / \mathrm{m}^{2} \mathrm{~d}\right) . H$ is the heat of melting, where the subscript $\mathbf{R}$ is net radiation, $\mathbf{S}$ is sensible heat, $\mathrm{L}$ is latent heat, $\mathrm{C}$ is conduction of heat, and $\mathrm{P}$ is precipitation.

The terms $H_{\mathrm{R}}, H_{\mathrm{S}}$, and $H_{\mathrm{L}}$ are subject to changes by climatic perturbations, while $H_{\mathrm{C}}$ and $H_{\mathrm{p}}$ are assumed to be constant. reads

By introducing climatic perturbations, Equation

$$
\delta H=\delta H_{\mathrm{R}}+\delta H_{\mathrm{S}}+\delta H_{\mathrm{L}} \quad \text { with } \delta H_{\mathrm{C}}=\delta H_{\mathrm{P}}=0
$$

where

$$
\begin{aligned}
& \delta H_{\mathrm{R}}=\left(\alpha^{\prime} \delta T_{\mathrm{a}}+\beta \delta w\right) f, \\
& \delta H_{\mathrm{S}}=\left(\alpha \delta T_{\mathrm{a}}\right) f, \\
& \delta H_{\mathrm{L}}=\left(\varphi \delta \rho_{\mathrm{v}}\right) f .
\end{aligned}
$$

$\delta T_{\mathrm{a}}, \delta w$, and $\delta \rho_{\mathrm{y}}$ are climatic perturbations of air temperature, cloudiness, and absolute humidity, and $\alpha, \alpha^{\prime}$, $\beta$, and $\varphi$ are factors of proportionality modelling local heatflux densities. The term $f$ is a non-dimensional number for modelling the altitudinal profile of the heat-flux densities. $\tau$ and $H$ are decreasing functions of altitude (Figs 1 and 2) with the conditions $\tau=0$ and $H=0$ at the same altitude. From these conditions, the numerical value of the nondimensional number $f$ is obtained. Combining Equation (5) with Equations (6), it reads

$$
\delta H=\mu_{1} \delta T_{\mathrm{a}}+\mu_{2} \delta \rho_{\mathrm{v}}+\mu_{3} \delta \mathrm{w}
$$

with the numerical values of the coefficients

$$
\begin{aligned}
& \mu_{1}=\left(\alpha+\alpha^{\prime}\right) f \quad \mu_{1}=0.803 \mathrm{MJ} \mathrm{m}^{-2} \mathrm{~d}^{-1} \mathrm{~K}^{-1}, \\
& \mu_{2}=\varphi f \quad \mu_{2}=1.272 \mathrm{MJ} \mathrm{m}^{-2} \mathrm{~d}^{-1} \text { per } \mathrm{g} \mathrm{m}^{-3} \text { vapour, } \\
& \mu_{3}=B f \quad \mu_{3}=-0.045 \mathrm{MJ} \mathrm{m}^{-2} \mathrm{~d}^{-1} \text { per tenth }
\end{aligned}
$$

While factors $\alpha, \alpha^{\prime}$, and $\beta$ have been explained previously in detail (Ambach, 1985a), in the present study for the first time changes of the latent heat-flux density due to climatic perturbations are taken into account by the factor $\varphi$. After conversion of units, from Ambach and Kirchlechner (1986, equations (20) and (21)) $\varphi=2.63 \mathrm{MJ}$ $\mathrm{m}^{-2} \mathrm{~d}^{-1}$ per $\mathrm{g} \mathrm{m}^{-3}$ vapour and $\mu_{2}=1.272 \mathrm{MJ} \mathrm{m}^{-2} \mathrm{~d}^{-1}$ per $\mathrm{g} \mathrm{m}^{-3}$ vapour result. These values correspond to the case of evaporation at a wind velocity of $7 \mathrm{~m} \mathrm{~s}^{-1}$ and are weighted means of $2: 1$ of corresponding values for snow and ice surfaces due to superimposed ice formation (Ambach, 1985a).

The change in heat-flux of melting at the equilibriumline altitude under perturbed conditions results from both the climatic perturbations (Equation (9a)) and the shift in altitude (Equation (9b)). It holds

$$
\begin{gathered}
H=H_{0}+\delta H+(\partial H / \partial z) \Delta h \\
\delta H=\mu_{1} \delta T_{\mathrm{a}}+\mu_{2} \delta \rho_{\mathrm{v}}+\mu_{3} \delta w
\end{gathered}
$$$$
(\partial H / \partial z) \Delta h=\left[\mu_{1}\left(\partial T_{\mathrm{a}} / \partial z\right)+\mu_{2}\left(\partial \rho_{\mathrm{v}} / \partial z\right)+\mu_{3}(\partial w / \partial z)\right] \Delta h .
$$

The factors $\mu_{1}, \mu_{2}, \mu_{3}$ and the gradients $\partial T_{\mathrm{a}} / \partial z, \partial \rho_{\mathrm{v}} / \partial z$, and $\partial w / \partial z$ are assumed to be constants independent of altitude. $\Delta h$ is the difference in altitude related to the present equilibrium-line altitude.

\subsection{Number of ablation days}

The number of ablation days depends on the seasonal course of the air temeprature. It is affected by perturbations of air temperture and depends on altitude. Starting with a measured series of $T_{\mathrm{a}}\left(t, z_{1}\right)$ at an altitude $z_{1}$, the function $T_{\mathrm{a}}(t, z)$ at any altitude $z$ is obtained by applying the altitudinal gradient of the air temperature. The method has been described in detail by Ambach (1977, p. 53).

The altitudinal gradient of temperature of $-0.0073 \mathrm{~K} \mathrm{~m}^{-1}$ was determined by comparing daily mean temperatures at Jakobshavn $(40 \mathrm{~m}$ a.s.1.) and Camp IV-EGIG (1013 m a.s.l.) during the period of measurements in 1959 (Ambach, 1977, fig. 19, p. 36). An anonymous referee proposed a value of $-0.0057 \mathrm{~K} \mathrm{~m}^{-1}$ was valid for the months June-August. The difference may be due to thermal advection in the ice-free area or may be explained by frequent katabatic winds. However, the ablation-days method is open to varying numerical applications.

Figure 1 shows the number of ablation days averaged for 1958-71 as a function of altitude and of air temperature. The $\Delta T_{\text {a }}$ scale is converted into the $\Delta h$ scale by $\partial T_{\mathrm{a}} / \partial z=-0.0073 \mathrm{~K} \mathrm{~m}^{-1}$. In Figure $1, \Delta T_{\mathrm{a}}$ can be substituted by the perturbation $\delta T_{\mathrm{a}}$ when searching for the number of ablation days.

The change in the number of ablation days at the equilibrium-line altitude under perturbed conditions results from both the perturbation in air temperature (Equation (10a)) and the change in altitude (Equation (10b)). It holds for

$$
\begin{array}{rlrl}
\tau & =\tau_{0}+\delta \tau+(\partial \tau / \partial z) \Delta h, \\
\delta \tau & =\gamma \delta T_{\mathrm{a}}, \\
(\partial \tau / \partial z) \Delta h & =\gamma \Delta T_{\mathrm{a}} \text { with } \Delta T_{\mathrm{a}}=\left(\partial T_{\mathrm{a}} / \partial z\right) \Delta h, \\
\gamma & =10.4-0.011 \Delta h \mathrm{~d} \mathrm{~K}^{-1} & \text { for } \Delta h>-274 \mathrm{~m}, \\
\gamma & =13.5 \mathrm{~d} \mathrm{~K}^{-1} \quad \text { for } \Delta h<-274 \mathrm{~m} .
\end{array}
$$

As $\gamma$ is not constant, the effect of $\delta T_{\mathrm{a}}$ on $T$ depends on altitude. In previous analyses (Ambach, 1985a; Ambach and Kuhn, 1985) a constant number of ablation days was applied to the initial and shifted equilibrium-line altitude, independent of climatic perturbations and of shift in altitude. This is only correct if the changes numerically derived from Equations ( $10 \mathrm{a}$ and $\mathrm{b}$ ) compensate each other. However, the present study shows that the influence on the number of ablation days by a climatic perturbation is not fully compensated by the corresponding shift in altitude. For example, the number of ablation days is changed due 


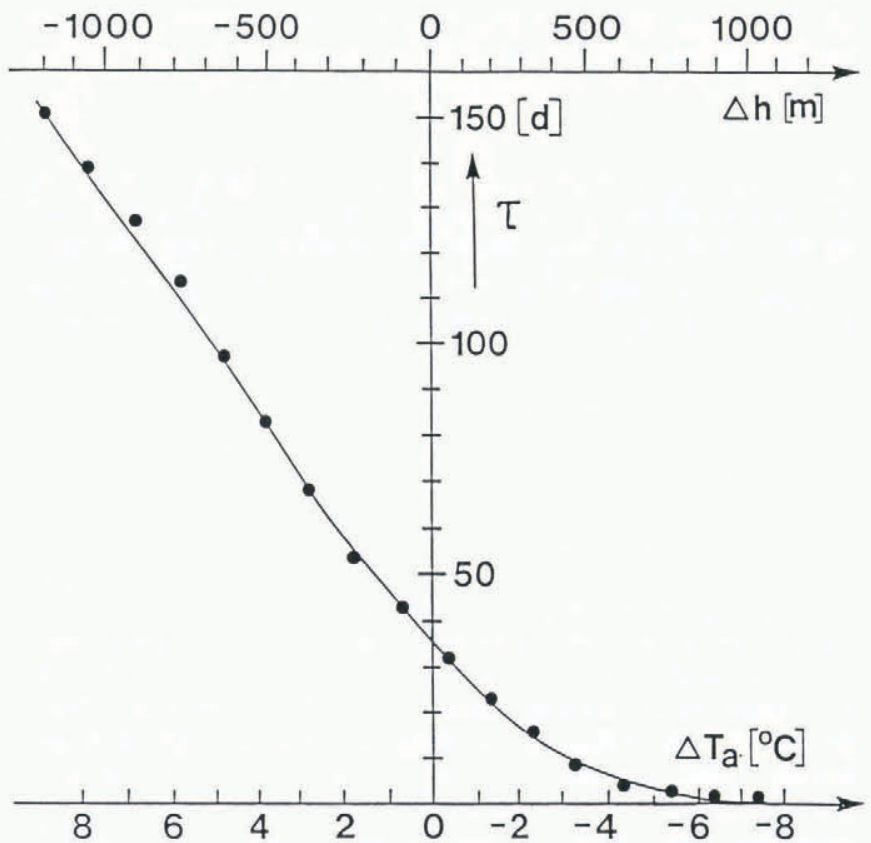

Fig. 1. Number of ablation days ( $\tau$ ) as a function of altitude $(\Delta h)$ and air temperature $\left(\Delta T_{a}\right)$ averaged for 1958-71. $\Delta h=0$ and $\Delta T_{a}=0$ denote the present equilibrium-line altitude.

to the perturbation $\delta T_{\mathrm{a}}=+1 \mathrm{~K}$ by $\delta \tau=9.4 \mathrm{~d}$ (Equation (10a)) and due to the change in equilibrium-line altitude by $(\partial \tau / \partial z) \Delta h=-6.0 \mathrm{~d}$ (Equation (10b)). As a consequence, a total change of $+3.4 \mathrm{~d}$ results. Therefore, it is concluded that the change of the number of ablation days is an important point.

\section{SHIFT OF THE EQUILIBRIUM-LINE ALTITUDE BY CLIMATIC PERTURBATIONS}

By applying perturbation analysis, Equation (1) is transformed into

$$
\begin{gathered}
{\left[\tau_{0}+\delta \tau+(\partial \tau / \partial z) \Delta h\right]\left[H_{0}+\delta H+(\partial H / \partial z) \Delta h\right]=} \\
=k L\left[c_{0}+\delta c+(\partial c / \partial z) \Delta h\right]
\end{gathered}
$$

where $\delta \tau, \delta H$, and $\delta c$ are climatic perturbations. $\delta \tau$ and $\delta H$ are obtained from Equations (9a) and (10a), while $\delta c$ is an arbitrary value. The terms $(\partial \tau / \partial z) \Delta h,(\partial H / \partial z) \Delta h$, and $(\partial c / \partial z) \Delta h$ are changes due to the shift in altitude. $\partial \tau / \partial z$ and $\partial H / \partial z$ are obtained from Equations (9b) and (10b), while $\partial c / \partial z$ is a measured value. The shift of the equilibrium-line altitude $\Delta h$ can be determined from Equation (11) when the climatic perturbations are introduced.

In Figure 2, the annual accumulation and the heat-flux density of melting are linear functions of altitude, whereas the number of ablation days is a non-linear function. The non-linearity is taken into account by the non-constant factor $\gamma$ in Equations (10a and b). Figure 2 shows that $\delta c$, $\delta H, \delta \tau$, and the corresponding terms $(\partial c / \partial z) \Delta h,(\partial H / \partial z) \Delta h$, and $(\partial \tau / \partial z) \Delta h$ have opposite signs. The climatic perturbations are partly compensated by the altitudinal shifts. As a consequence, climatic perturbations are attenuated by the shift of the equilibrium-line altitude.

For example, a perturbation in air temperature $\delta T_{\mathrm{a}}$ of $1 \mathrm{~K}$ results in a shift of the equilibrium-line altitude $\Delta h$ by $87.5 \mathrm{~m}$. At this altitude the temperature is lower by $-0.64 \mathrm{~K}$ compared with the temperature at the initial altitude due to the altitudinal gradient of air temperature. Therefore, at the equilibrium line under perturbed conditions the effective change in temperature amounts to $+0.36 \mathrm{~K}$ instead of $+1 \mathrm{~K}$.

In the case of decreasing annual accumulation with altitude $[(\partial c / \partial z)<0]$, this compensation is not effective. As a consequence, the shift of the equilibrium-line altitude is
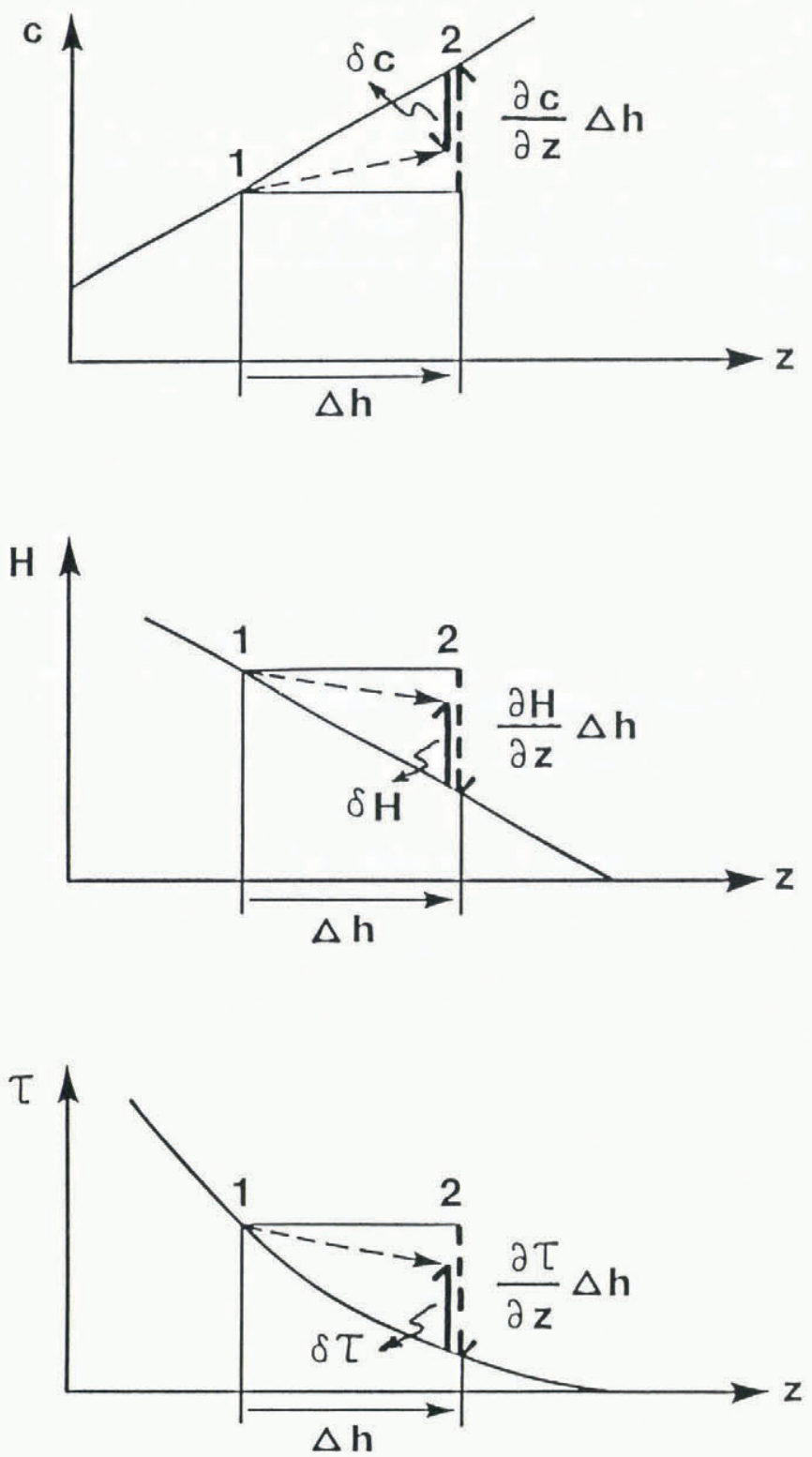

Fig. 2. Annual accumulation (c), heat-flux density of melting $(H)$, and number of ablation days $(\tau)$ versus altitude. 1 and 2 indicate the equilibrium-line altitudes in initial and perturbed conditions, respectively.

amplified, and therefore instabilities in the ablation regime may occur (Ambach, 1988; and section 7).

The equilibrium-line altitude can be obtained graphically from intersection of the following two functions:

$$
\begin{gathered}
Q_{\mathrm{H}}(\Delta h)=\left[\tau_{0}+\delta \tau+(\partial \tau / \partial z) \Delta h\right]\left[H_{0}+\delta H+(\partial H / \partial z) \Delta h\right] \\
Q_{\mathrm{C}}(\Delta h)=k L\left[c_{0}+\delta c+(\partial c / \partial z) \Delta h\right]
\end{gathered}
$$

where $Q_{\mathrm{H}}(\Delta h)$ and $Q_{\mathrm{C}}(\Delta h)$ correspond to the left-hand side and the right-hand side of Equation (11), respectively. $Q_{\mathrm{H}}(\Delta h)$ is the heat-flux density of melting originating from the heat balance, and $Q_{\mathrm{C}}(\Delta h)$ is the heat of melting required for the annual accumulation plus superimposed ice. In Figure 3, both functions are shown versus altitude, where $\Delta h=0$ is the present-day equilibrium-line altitude. The non-linear graphs represent $Q_{\mathrm{H}}(\Delta h)$ for $-3 \mathrm{~K}<T_{\mathrm{a}}<$ $+3 \mathrm{~K}$, and the straight lines represent $Q_{\mathrm{C}}(\Delta h)$ for $\partial c / \partial z=$ $0.55 \mathrm{~kg} \mathrm{~m}^{-2} / \mathrm{m}$ and $\partial c / \partial z=0$. Each point of intersection of the straight lines with non-linear functions is a possible position of the equilibrium line. From Figure 3 it can be shown that decreasing gradients of annual accumulation displace the point of intersection to a greater equilibriumline altitude. This means an enhanced sensitivity of the equilibrium-line altitude to climatic perturbations. 


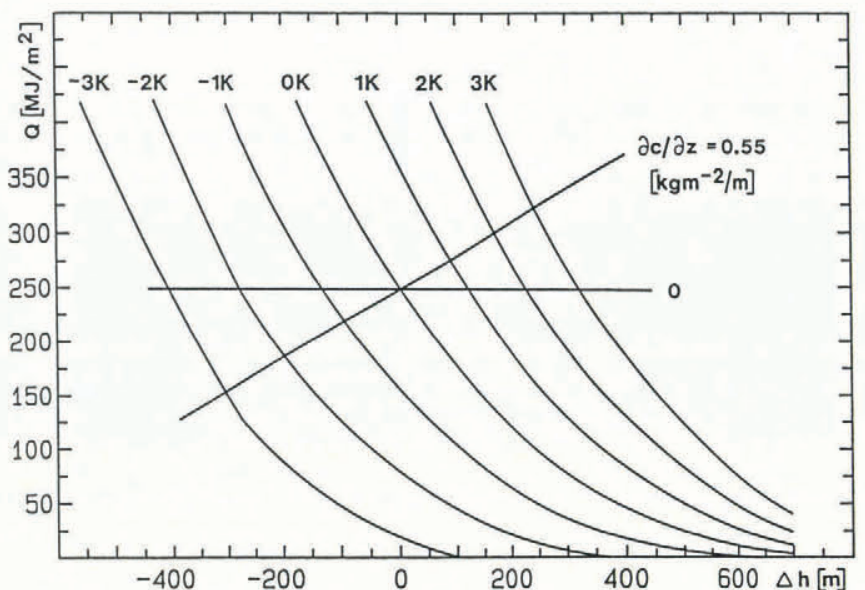

Fig. 3. Heat-flux density of melting for the entire ablation period (Q) versus altitude ( $\Delta h)$ for $-3 K \leqslant 8 T_{a} \leqslant+3 K$ (curved lines) and heat of melting for the annual accumulation with altitudinal gradients $0.55 \mathrm{~kg} \mathrm{~m}^{-2} / \mathrm{m}$ and zero, respectively (straight lines). $\Delta h=0$ denotes the present equilibrium-line altitude.

Table I shows the altitudinal shift of the equilibrium line in the western EGIG profile for reasonable values of perturbations. The dominant influence of $\delta T_{\mathrm{a}}$ originates from the fact that air temperature controls both heat-flux density of melting and number of ablation days. $\delta c=$ $50 \mathrm{~kg} \mathrm{~m} \mathrm{~m}^{2}$ is about $10 \%$ of the annual accumulation, measured

TABLE I. SHIFT OF THE EQUILIBRIUM-LINE ALTITUDE BY CLIMATIC PERTURBATIONS AT THE EGIG PROFILE

$\begin{array}{ccccc}\Delta h & \delta T_{\mathrm{a}} & \delta \rho_{\mathrm{v}} & \delta w & \delta c \\ \mathrm{~m} & \mathrm{~K} & \mathrm{~g} \mathrm{~m}^{-3} & & \mathrm{~kg} \mathrm{~m}^{-2} \\ +87.5 & +1 & 0 & 0 & 0 \\ +9.8 & 0 & +0.25 & 0 & 0 \\ -4.9 & 0 & 0 & +1 / 10 & 0 \\ -24.3 & 0 & 0 & 0 & +50\end{array}$
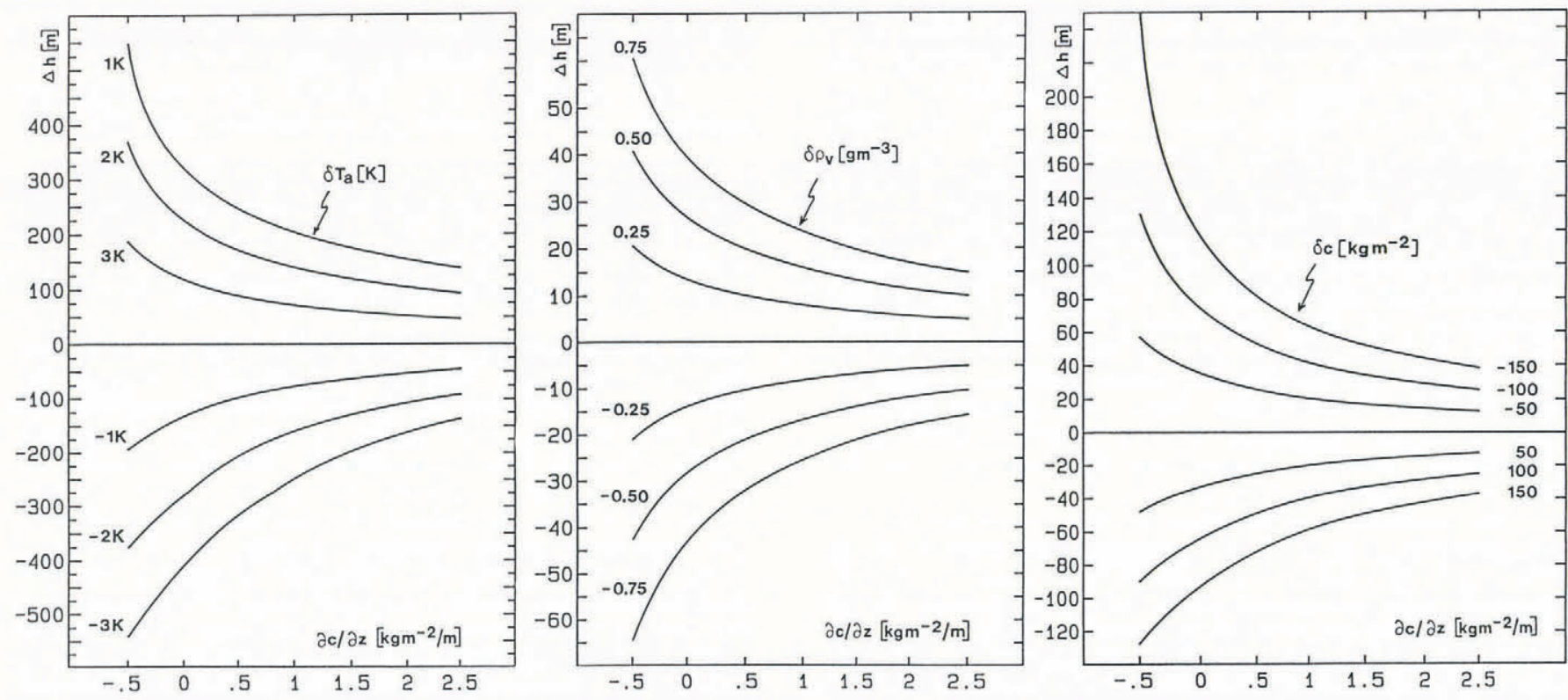

Fig. 4. Altitudinal shift of the equilibrium line versus the gradient of annual accumulation for perturbations of air temperature $\delta T_{a}$ (left), absolute humidity $\delta \rho_{v}$ (center) and annual accumulation $\delta c$ (right). 


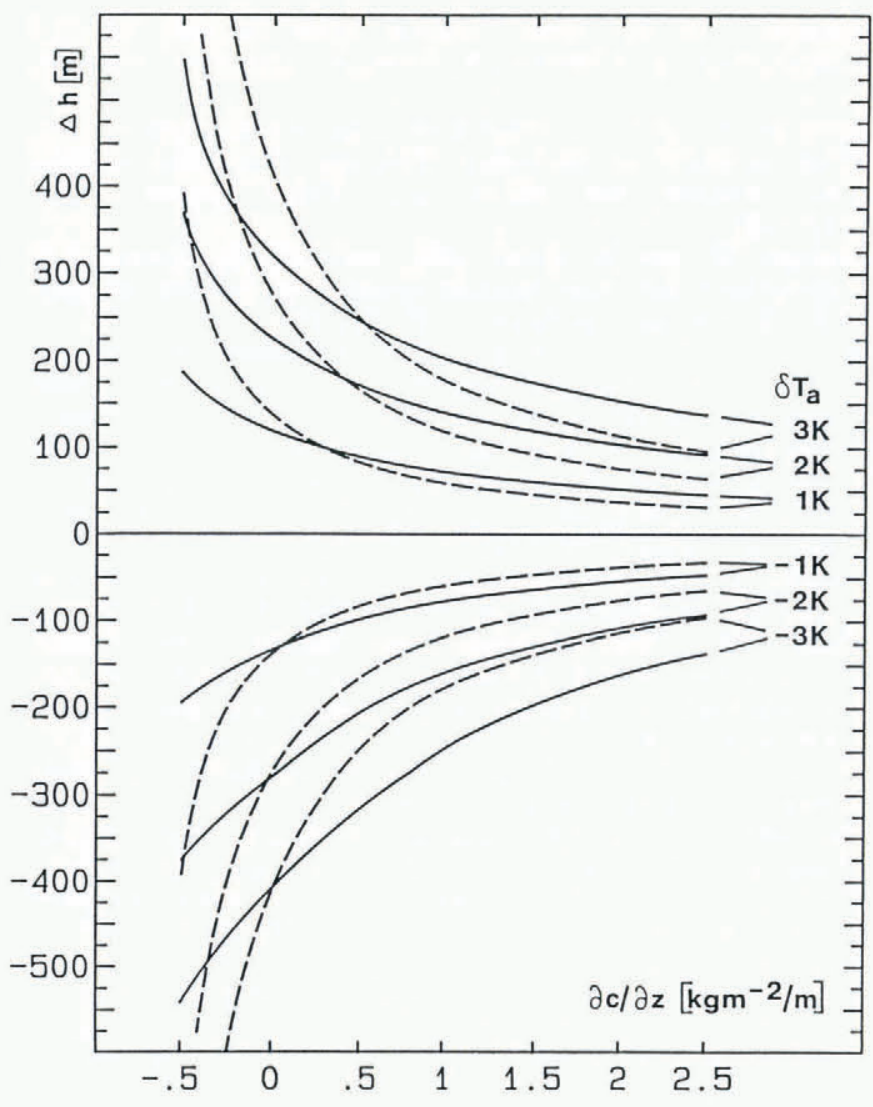

Fig. 5. Altitudinal shift of the equilibrium line versus the gradient of annual accumulation for perturbations of air temperature. Dashed lines: previous model with $\tau=\tau_{0}$ (constant) and $\partial \rho_{\nu} / \partial z=0$. Full lines: present study.

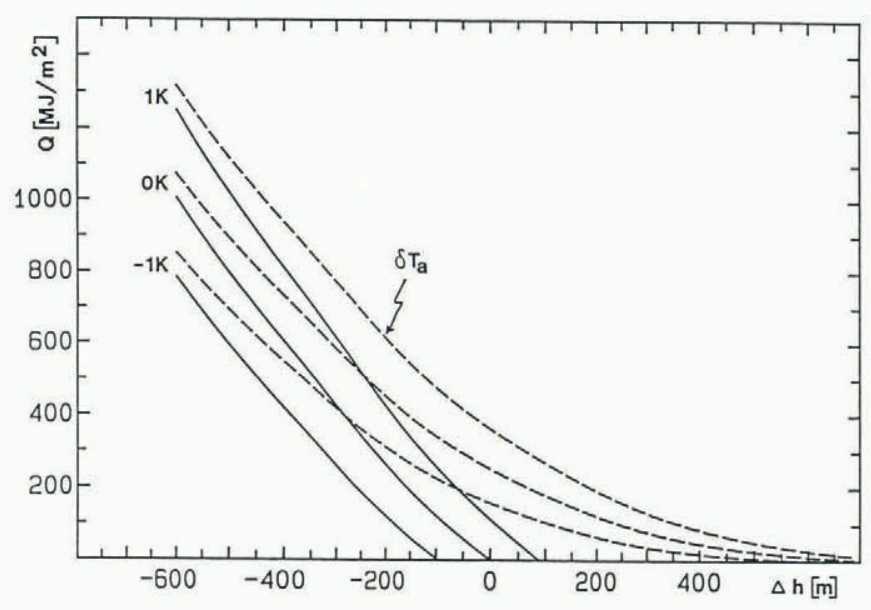

Fig. 6. Heat of melting for the entire ablation period (Q) versus altitude $(\Delta h)$ for perturbations $\delta T_{a}=-1 K, 0 K,+1 K$. Dashed lines represent the heat of melting for snow plus superimposed ice plus old glacier ice $\left(Q_{\mathrm{S}}+Q_{\mathrm{SI}}+Q_{\mathrm{I}}\right.$; Equation (14)); full lines represent the heat of melting for old glacier ice $\left(Q_{\mathrm{I}}^{*}\right)$.

where the subscripts mean snow, superimposed ice, and ice (more exactly, old glacier ice). At the equilibrium line $Q_{\mathrm{I}}=0$.

For complete superimposed ice formation, according to section 4:

$$
\begin{aligned}
Q_{\mathrm{S}}(\Delta h) & =(2 / 3) L c(\Delta h), \\
Q_{\mathrm{SI}}(\Delta h) & =L c(\Delta h), \\
Q_{\mathrm{I}}(\Delta h) & =Q_{\mathrm{H}}(\Delta h)-(5 / 3) L c(\Delta h),
\end{aligned}
$$

with

$$
c(\Delta h)=c_{0}+(\partial c / \partial z) \Delta h
$$

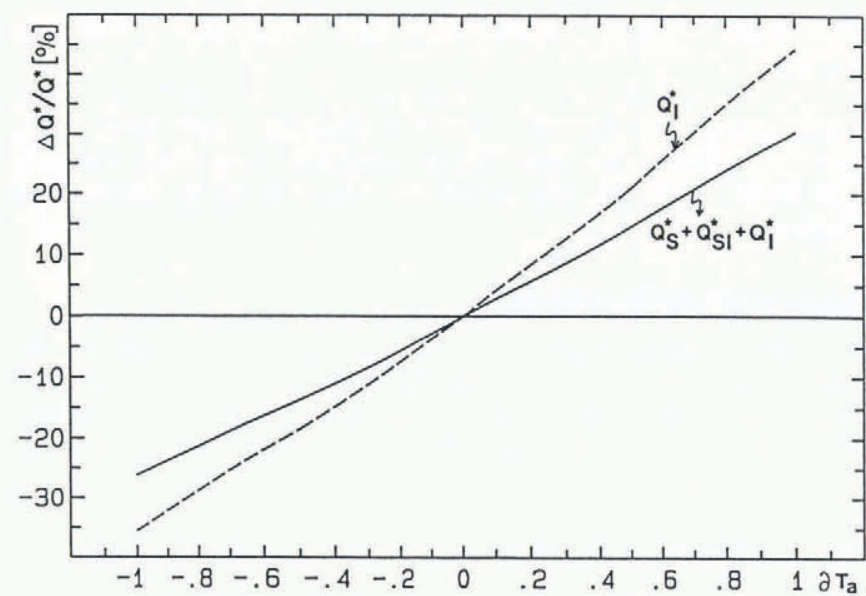

Fig. 7. Relative change of the heat of melting for the entire ablation period and the range of altitude versus perturbations of air temperature. The dashed line is related to the heat of melting for old glacier ice $\left(Q_{\mathrm{I}}^{*}\right.$, corresponding to the net ice ablation; Equation (20)). The full line represents the heat of melting for snow plus superimposed ice plus old glacier ice $\left(Q_{\mathrm{H}}{ }^{*}=Q_{\mathrm{S}}{ }^{*}+\right.$ $Q_{\mathrm{SI}}{ }^{*}+Q_{\mathrm{I}}^{*} ;$ Equation (19)).

The symbols are the same as in Equations (13) and (14). $Q_{\mathrm{I}}(\Delta h)$ is the heat of melting related to the net ice ablation, while $(5 / 3) L c(\Delta h)$ is the heat of melting required for snow plus superimposed ice. By integration of $Q_{\mathrm{H}}(\Delta h)$ and $Q_{\mathrm{I}}(\Delta h)$ over the range of altitude, the heat of melting is obtained and this is effective over the altitudinal range:

$$
\begin{aligned}
Q_{\mathrm{H}}{ }^{*} & =\int Q_{\mathrm{H}}(\Delta h) \mathrm{d} h \\
Q_{\mathrm{I}}^{*} & =\int Q_{\mathrm{I}}(\Delta h) \mathrm{d} h
\end{aligned}
$$

where the lower limit of integration is the ice margin $(\Delta h=$ $-600 \mathrm{~m})$ and the corresponding upper limits of integration are obtained by the conditions $Q_{\mathrm{H}}(\Delta h)=0$ and $Q_{\mathrm{I}}(\Delta h)=0$, respectively. The terms $Q_{\mathrm{H}}{ }^{*}$ and $Q_{\mathrm{I}}{ }^{*}$ (Equations (19) and (20)) mean the heat of melting over the altitudinal range within a strip of unit width. $Q_{\mathrm{H}}{ }^{*}$ is the entire heat-flux density of melting originating from the heat balance and $Q_{\mathrm{I}}^{*}$ is the part related to the net ice ablation.

In Figure 7 , the relative changes of $Q_{\mathrm{H}}{ }^{*}$ and $Q_{\mathrm{I}}{ }^{*}$ are shown for $-1 \mathrm{~K} \leqslant T_{3} \leqslant+1 \mathrm{~K}$. With $\delta T_{2}=+1 \mathrm{~K}$, an increase of about $45 \%$ is obtained for $Q_{\mathrm{I}}^{*}$ corresponding to the same relative change in net ice ablation and an increase of about $30 \%$ results for $Q_{\mathrm{H}}{ }^{*}$, which is related to the entire heat-flux density of melting (snow, superimposed ice, plus old glacier ice). Strictly speaking, these results are related to the surface-ablation regime. Melt water may partly refreeze in the lower ablation area and, in the case of refreezing, melting cannot be interpreted as a loss of mass (Ambach, in press).

\section{FINAL REMARKS}

Most estimates of the present mass balance of the Greenland ice sheet suggest that gains and losses are about equal (National Academy of Sciences, 1985, table 1, p. 2). Within the next few decades, a significant increase in temperature is predicted at high latitudes due to the increase in $\mathrm{CO}_{2}$ concentration and other greenhouse gases in the atmosphere. From enhanced ice melt in Greenland, a sea-level rise of between 0.1 and $0.3 \mathrm{~m}$ to the year 2100 A.D. is estimated.

On the Greenland ice sheet, a shift of the equilibriumline altitude of about $500 \mathrm{~m}$ is likely due to a temperature rise of $6 \mathrm{~K}$ and a simultaneous increase in precipitation of about $10 \%$. From the above results, it is concluded that the rise in temperature is the controlling factor, while changes in precipitation and humidity are of minor importance. Effects from cloudiness can even be neglected as cloudiness 
oppositely affects short-wave and long-wave radiation balances.

The sensitivity of sea-level to a shift in the equilibrium line is still uncertain because melt water may partly refreeze in the lower ablation area and iceberg discharge may be perturbed by the changing rheological regime.

\section{ACKNOWLEDGEMENTS}

This manuscript is part of a project which is financially supported by the Österreichische Akademie der Wissenschaften, Wien. The author thanks Professor M. Kuhn for critical discussions and $\mathrm{Mr}$ J. Huber for co-operation in evaluation of the data.

\section{REFERENCES}

Ambach, W. 1963. Untersuchungen zum Energieumsatz in der Ablationszone des grönländischen Inlandeises (Camp IV-EGIG $\left.69^{\circ} 40^{\prime} 05^{\prime \prime} \mathrm{N}, \quad 49^{\circ} 37^{\prime} 58^{\prime \prime} \mathrm{W}\right)$. Medd. Gronl., 174(4).

Ambach, W. 1977. Untersuchungen zum Energieumsatz in der Ablationszone des grönländischen Inlandeises. Nachtrag. Medd. Gronl., 187(5).

Ambach, W. 1985a. Characteristics of the heat balance of the Greenland ice sheet for modelling. J. Glaciol., 31(107), 3-12.

Ambach, W. 1985b. Climatic shift of the equilibrium line: Kuhn's concept applied to the Greenland ice cap. Ann. Glaciol., 6, 76-78.

Ambach, W. 1988. Instabilities of the equilibrium line altitude in Greenland by climatic warming. Eidg. Tech. Hochschule, Zürich. Versuchsanst. Wasserbau, Hydrol. Glaziol. Mitt. 94, 51-57.
Ambach, W. In press. Surface mass balance of the Greenland ice sheet and climatic warming. Climatic Change.

Ambach, W. and P. Kirchlechner. 1986. Nomographs for the determination of meltwater from ice- and snow surfaces by sensible and latent heat. Wetter Leben, 38(4), 181-189.

Ambach, W. and M. Kuhn. 1985. Accumulation gradients in Greenland and mass balance response to climatic changes. Z. Gletscherkd. Glazialgeol., 21, 311-317.

Ambach, W. and M. Kuhn. 1989. Altitudinal shift of the equilibrium line in Greenland calculated from heat balance characteristics. In Oerlemans, J., ed. Glacier Fluctuations and Climatic Change. Proceedings of the Symposium on Glacier Fluctuations and Climatic Change held in Amsterdam, 1-5 June 1987. Dordrecht, etc., Kluwer Academic Publishers, 281-288.

Benson, C.S. 1962. Stratigraphic studies in the snow and firn of the Greenland ice sheet. SIPRE Res. Rep. 70.

Kuhn, M. 1981. Climate and glaciers. International Association of Hydrological Sciences Publication 131 (Symposium at Canberra - Sea Level, Ice, and Climatic Change), 3-20.

Kuhn, M. 1987. Micrometeorological conditions for snow melt. J. Glaciol., 33(113), 24-26.

Oerlemans, J., ed. 1989. Glacier Fluctuations and Climatic Change. Proceedings of the Symposium on Glacier Fluctuations and Climatic Change held in Amsterdam, 1-5 June 1987. Dordrecht, etc., Kluwer Academic Publishers.

U.S. Department of Energy. 1985. Glaciers, Ice Sheets and Sea Level: Effect of a $\mathrm{CO}_{2}$-Induced Climatic Change. Report of a Workshop held in Seattle, Washington, September 13-15, 1984. Washington, DC, U.S. Department of Energy. 